\title{
Professionalism in Engineering Technology: A Study of Final Course Grades, Student Professionalism, Attendance, and Punctuality
}

\author{
Jeffrey M. Ulmer
}

\begin{abstract}
Final course grades and professionalism grades were compared to determine statistically significant differences for (1) students with $90 \%$ or higher final course grades, (2) students with 80-90\% final course grades, (3) students with $70-80 \%$ final course grades, (4) students with $0-70 \%$ final course grades, and (5) all students with a final course grade. Forty-one engineering technology courses were offered over 16 semesters (fall 2013 through fall 2018) in 100\% online, face-to-face, and hybrid formats. Student populations were both undergraduate and graduate (master's) students in engineering technology courses at one Midwestern university. A total of 729 students were involved in the study. Study results indicate that professionalism grades, in terms of attendance and punctuality, were high (median of 93.33-100\%) for students earning $80-100 \%$ median final course grades. Students earning $70-80 \%$ mean final course grades were less motivated to earn high professionalism gradesearning a $75.20 \%$ mean. There was little difference between final course grades and professionalism grades for students earning less than a $70 \%$ median for a final course grade. The aggregate of all student final course grades (median of $91.35 \%$ ) in comparison to professionalism grades (median of $98.28 \%$ ) yielded a significant difference.
\end{abstract}

Keywords: Attendance, Education, Professionalism, Student Grades

In Merriam-Webster, professionalism is defined as "the conduct, aims, or qualities that characterize or mark a profession or a professional person" ("Professionalism," 2019). At one Midwestern university, professionalism is demonstrated through attendance, punctuality, and assignment deadline behavior. Students are offered the choice of participating in one course section via a face-to-face classroom format or a $100 \%$ online format. Classroom students earn attendance points by attending scheduled classroom sessions, and online students earn attendance points through the submission of online discussion board session screen-capture videos (asynchronous delivery) according to scheduled dates and times. Punctuality for classroom students is merely arriving to class on time; however, for online students, punctuality is turning in the online discussion board session screen-capture videos on or before the scheduled date and time. Assignment deadline behavior is demonstrated by turning in assignments and other class activities on or before the scheduled date 
and time. Students are provided with the opportunity to earn $25 \%$ of their total potential course points through the attendance and punctuality portion of professionalism. The remaining assignment deadline behavior points are accounted for through student performance on assignments and other activities.

National data for the 2015-2016 school year showed that approximately eight million students, one out of seven students, were chronically absent, meaning that they missed 15 or more days of school (Blad, 2018). This is an academic problem that is not easily solved. Many of these absent students fail to realize that, as Woody Allen has said, "“80\% of success is showing up"' (Moore, 2006, p. 26). To make matters worse, class attendance decreases as an academic semester progresses (Marburger, 2001; Rodgers, 2001; Stripling, Roberts, \& Israel, 2013; Van Blerkom, 1992; Zhao \& Stinson, 2006). Professionalism, with absenteeism as one of the critical elements, is an individual activity (Klay, Brower, \& Williams, 2001). As the science fiction movie "The Fifth Element" had a critical element to spare the universe from destruction, "class attendance is a critical ingredient [or element] for developmental education students' academic success" (Moore, 2004, p. 35). Although the literature review did not yield data or commentary on student punctuality and turning in assignments and activities on time, student attendance was well researched in academic journals. Therefore, this study is primarily a replication of a student attendance study $(n=$ 698) conducted by Moore (2005).

\section{Significance and Purpose of the Study}

This study is significant in drawing attention to the term professionalism as supported in the academic classroom and $100 \%$ online through the elements of attendance, punctuality, and assignment deadline behavior. Classroom- and online-demonstrated professionalism is a learned behavior that prepares students to be successful in their future careers. However, the importance of professionalism has been underestimated in the face of reports that student absenteeism can be as high as $25 \%$ (Friedman, Rodriguez, \& McComb, 2001) or even higher (Romer, 1993) in some universities. "In college classrooms throughout the country, seats are empty" (Moore, 2005, p. 26).

The purpose of this study was to learn if students earn higher final course grades when professionalism is demonstrated through attendance and punctuality? Punctuality was included in the study because $25 \%$ of a student's total potential course points were earned through the attendance and punctuality portion of professionalism. Thomas and Higbee (2000) stated it best: "Nothing replaces being present in class" (p. 229)."

\section{Research Question and Hypothesis Statements}

The research question is: Do students earn higher final course grades when student professionalism is demonstrated through attendance and punctuality? From this question, the following null and alternative hypotheses were developed. 
- $\mathrm{H}_{01}: \mu 1=\mu 2$. There is no statistically significant difference between students with $90 \%$ or higher final course grades in comparison to professionalism grades in terms of attendance and punctuality.

- $\mathrm{H}_{\mathrm{A} 1}: \mu 1 \neq \mu 2$. There is a statistically significant difference between students with $90 \%$ or higher final course grades in comparison to professionalism grades in terms of attendance and punctuality.

- $\mathrm{H}_{02}: \mu 1=\mu 2$. There is no statistically significant difference between students with $80-90 \%$ final course grades in comparison to professionalism grades in terms of attendance and punctuality.

- $\mathrm{H}_{\mathrm{A} 2}: \mu 1 \neq \mu 2$. There is a statistically significant difference between students with $80-90 \%$ final course grades in comparison to professionalism grades in terms of attendance and punctuality.

- $\mathrm{H}_{03}: \mu 1=\mu 2$. There is no statistically significant difference between students with $70-80 \%$ final course grades in comparison to professionalism grades in terms of attendance and punctuality.

- $\mathrm{H}_{\mathrm{A} 3}: \mu 1 \neq \mu 2$. There is a statistically significant difference between students with $70-80 \%$ final course grades in comparison to professionalism grades in terms of attendance and punctuality.

- $\mathrm{H}_{04}: \mu 1=\mu 2$. There is no statistically significant difference between students with $0-70 \%$ final course grades in comparison to professionalism grades in terms of attendance and punctuality.

- $\mathrm{H}_{\mathrm{A} 4}: \mu 1 \neq \mu 2$. There is a statistically significant difference between students with $0-70 \%$ final course grades in comparison to professionalism grades in terms of attendance and punctuality.

- $\mathrm{H}_{05}: \mu 1=\mu 2$. There is no statistically significant difference between all student final course grades in comparison to professionalism grades in terms of attendance and punctuality.

- $\mathrm{H}_{\mathrm{A} 5}: \mu 1 \neq \mu 2$. There is a statistically significant difference between all student final course grades in comparison to professionalism grades in terms of attendance and punctuality.

\section{Assumptions of the Study}

The following assumptions were made for this study.

1. Student-instructor interaction and teaching styles did not affect the study.

2. Student motivation and performance were not affected by course delivery type ( $100 \%$ online, face-to-face, or hybrid) or topic matter.

3. Students participated to the best of their ability in all courses.

4. The study is not biased toward or against any student type (undergraduate or graduate), gender (female or male), age, or cultural background. 
5. Grades earned by students are generalizable to any student.

6. Paired-samples $t$-test grade differences are parametric (normally distributed), continuous, and were randomly and independently acquired.

7. Wilcoxon signed-rank test grade differences are nonparametric (not normally distributed), continuous, and were randomly and independently acquired.

\section{Limitations of the Study}

The following are limitations for this study.

1. Participants were both domestic and international students at one Midwestern university.

2. Some students may have lacked the motivation to study a topic (or topics).

3. Students may not have been academically prepared to take any class.

4. The results of this study may not be repeatable at another educational institution.

5. Violation of any of the paired-samples $t$-test assumptions would have created a limitation.

6. Violation of any of the Wilcoxon signed-rank test assumptions would have created a limitation.

\section{Traits of Professionalism}

\section{Literature Review}

Ritz and Bevins (2012) state that "citizens need basics for daily livelihoods, and less developed economies still rely on manual labor for their economies and survival of their people" (p. 101). Professionalism is one of those basics, and a high level of professionalism in attendance, punctuality, and meeting assignment (or project) deadlines is a core fundamental required for any company's success, regardless of the country in which they are located. A broad scope of professionalism is summed up in the 13 principles described by Ratanawongsa et al. (2006): "altruism, respect, sensitivity, accountability, confidentiality, communication and shared decision making, integrity, compassion and empathy, duty, competence, managing conflicts of interest, self-awareness, and commitment to excellence and ongoing professional development" (pp. 759760). In their study, participants identified three main barriers to professionalism: time constraints, workload, and the institution's culture. As a side note, Hollenbeck (2009) shared that professionalism is manifested by mentoring others and upholding personal dignity and the dignity of fellow associates.

Career readiness "can be simply described as the level of achievement a student needs to be ready to join and succeed in the marketplace" (Deif, Stark, 
Butler, \& Olsen, 2017, p. 3). As future employees, students exhibit elements of professionalism through their education, training, and value-added skills in their interactions with others (Ritz \& Bevins, 2012). Other elements for successful careers rely upon communication, problem-solving, and applied work (Davis \& McDonald, 2016; National Academy of Engineering, Committee on Standards for K-12 Engineering Education, 2010). Applied-work professionalism requires physical presence for colleague collaboration (Korhonen, 2003; Ritz \& Bevins, 2012).

\section{Customer Satisfaction}

Customer satisfaction is directly tied to the quality of products and customer service, including levels of under or over fulfillment. Like the business world, student performance in terms of low attendance, late class arrival, and late work may be a students' response due to a low satisfaction level (Flanigan, Benson, \& Porter, 2017; Oliver, 2010; Schunk, 2000). Low levels of student satisfaction may manifest itself in skipping class and affect other students as well (Stripling et al., 2013; Wyatt, 1992). The net effect results in decreased morale and lower academic success for a given course, which affects the entire class (Brauer, 1994; Moore, 2004, 2005). This is exacerbated when considering that a higher percentage of students are more likely to skip class on a Friday than on other days (Marburger, 2001). Student satisfaction is obtained through a sense of class community (Klay et al., 2001), although no amount of class attendance can overcome a student's lack of motivation to learn (Kahveci, 2010; Yau \& Cheng, 2012).

\section{Reasons to Skip Class}

Friedman, Rodriguez, and McComb (2001) state that class attendance is a puzzle. The reasons for class attendance are diverse and are different for each student not attending class. In a study by Gump (2004), students reported missing class for the following reasons: health, preoccupation, weather, personal choice, inconvenience, and preparedness (p. 52). Stripling, Roberts, and Israel (2013) found that students in their study chose to miss class for these top seven reasons: (1) "I have deadlines for other academic work," (2) "I am studying for a test in another course," (3) "I have already earned enough points for the grade I want," (4) "Class is before or after a test," (5) "I do not find the class challenging," (6) "I know the grade that I will receive," and (7) "I have not completed an assignment that is due" (p. 54). One element missing from this list is the student's need for financial support through college loans or part/full-time jobs while attending class (Sullivan, 2018).

Although some universities and community colleges mandate classroom attendance in their policies (Moore, 2005), many institutions view student attendance as optional (Moore, 2006; Romer, 1993). In a study by Friedman et 
al. (2001), students reported that earned grades or penalties for attendance did not promote student participation or affect their final course grades significantly.

Last but not least, one must also consider the effect that course instructors can have on student attendance. Does the instructor's demeanor promote a desire for students to attend class or skip it? Instructors also heavily affect a student's motivation to attend a class by their course policies. One element, according to Light (1990), is the essential ingredient of rapid student feedback on course work. According to Thomas and Higbee (2000),

The best ... teacher, no matter how intellectually stimulating, no matter how clear in providing explanations and examples, may not be able to reach the high-risk freshman who has no real interest in learning ... and will certainly not be successful with the student who fails to show up for class. (p. 231)

\section{Student Success}

According to Moore (2006), attendance is "an explicit expression of students' motivation for academic success" (p. 19). These students succeed when interpersonal and diverse student-learning methods are accounted for (Keith, Stastny, \& Brunt, 2016). Successful students are supported by welldesigned, properly placed, and utilized academic resources (Sullivan, 2018). Learning does not occur just because a student attended class; however, "students who make higher grades enjoy attending class, are more gradeconscious, or are more intrinsically committed to being engaged in their education" (Moore, 2005, p. 32).

Students understand that they will earn higher class grades through classroom attendance (Moore, 2006). In fact, students often start a new course with the intent of coming to all class sessions and earning a high overall class grade (Moore, 2005). Poor student academic success is often linked with a student's thought of making up for missed class periods. Rodgers (2001) found that attendance affected performance; for example, "a student with average attendance of 74 percent of classes would score between 1.3 and 3.4 percentage points lower than an otherwise identical student with perfect attendance" ( $p$. 293).

\section{Study Population and Time Frame}

\section{Methodology}

Forty-one engineering technology courses were offered over 16 semesters (fall 2013 through fall 2018) in 100\% online, face-to-face, and hybrid formats. Student populations were both undergraduate and graduate (master's) students in engineering technology courses at one Midwestern university. A total of 729 participants were involved in the study, including students from the United States and various countries around the world. 


\section{Variables}

The continuous variables present were professionalism grade and final course grade - both variables were converted to percentages. Variables such as class status (undergraduate or graduate), gender, age, course type ( $100 \%$ online, face-to-face, or hybrid), statistics anxiety level, academic background, and cultural differences were not considered.

\section{Statistical Analysis}

Final course grades and professionalism grades were compared to determine statistically significant differences for (1) students with $90 \%$ or higher final course grades, (2) students with 80-90\% final course grades, (3) students with $70-80 \%$ final course grades, (4) students with $0-70 \%$ final course grades, and (5) all students with a final course grade.

Once the preliminary statistics were run using IBM SPSS Version 24.0, at a significance level of 0.05 , it was determined that both the paired-samples $t$-test and the Wilcoxon signed-rank test were needed. Paired-samples $t$-tests were used for grade difference average data results that were parametric (normally distributed). Wilcoxon signed-rank tests were used for grade difference median data results that were nonparametric (not normally distributed).

According to Field (2013, p. 371), a paired-samples $t$-test is a parametric test used to measure the average difference between one assessment to the next, for one data measurement on one individual, and then tallies the averaging information of all data sets, for all individuals, to determine if a mean statistical difference exists between graded results. The assumptions for a paired-samples $t$-test state that grade differences are parametric (normally distributed), continuous, and are randomly and independently acquired. Note that only the grade differences must be parametric not the actual data distributions themselves (Field, 2013, p. 378).

Also, according to Field (2009, p. 552), a Wilcoxon signed-rank test compares grade differences to determine the sign of the differences (positive or negative) toward the calculation of statistical significance. This statistical test is equivalent to the dependent (paired-samples) $t$-test for parametric (normally distributed) data (see Field, 2009, p. 329), which measures the average difference between one assessment to the next, for one data measurement on one individual, and then tallies the averaging information of all data sets, for all individuals, to determine if a statistical difference exists between pretest and posttest median results.

\section{Hypothesis 1 Results}

\section{Statistical Study Results and Assumption Testing}

There was a statistically significant difference between students with $90 \%$ or higher final course grades $(n=413)$ in comparison to professionalism grades 
in terms of attendance and punctuality. Consequently, the null hypothesis was rejected, and the alternative hypothesis was retained with final course grades $(M d n=95.05 \%)$ in comparison to professionalism grades $(M d n=100.00 \%, z=$ -9.280, $p=0.000, r=-0.456$ ). Using Cohen's criteria for $r$, this was a moderate effect size (Minium, Clarke, \& Coladarci, 1999, p. 73). This level of effect size means that although statistically significant, the difference in medians is moderate. Regarding meeting assumptions for the Wilcoxon signed-rank test, per the Kolmogorov-Smirnov test, nonnormality was confirmed at $p=0.000$. As for the other two assumptions, both met requirements, were continuous, and were randomly and independently acquired.

\section{Hypothesis 2 Results}

There was a statistically significant difference between students with 80 to $90 \%$ final course grades $(n=202)$ in comparison to professionalism grades in terms of attendance and punctuality. Consequently, the null hypothesis was rejected, and the alternative hypothesis was retained with final course grades $(M d n=86.25 \%)$ in comparison to professionalism grades $(M d n=93.33 \%, z=-$ $7.516, p=0.000, r=-0.528)$. Using Cohen's criteria for $r$, this was a moderate effect size (Minium et al., 1999, p. 73). This level of effect size means that although statistically significant, the difference in medians is moderate. Regarding meeting assumptions for the Wilcoxon signed-rank test, per the Kolmogorov-Smirnov test, nonnormality was confirmed at $p=0.000$. As to the other two assumptions, both met requirements, were continuous, and were randomly and independently acquired.

\section{Hypothesis 3 Results}

There was a statistically significant difference between students with 70 to $80 \%$ final course grades $(n=73)$ in comparison to professionalism grades in terms of attendance and punctuality. Consequently, the null hypothesis was rejected, and the alternative hypothesis was retained with final course grades ( $\mathrm{M}$ $=81.65 \%)$ in comparison to professionalism grades, $M d n=75.20 \%, t(72)=$ $4.258, p=0.000, r=0.194$. Using Cohen's criteria for $r$, this was a low effect size (Minium et al., 1999, p. 73). This level of effect size means that although statistically significant, the difference in means is low. Regarding meeting assumptions for the paired-samples t-test, normality was confirmed with at $p=$ 0.074 . As to the other two assumptions, both met requirements, were continuous, and were randomly and independently acquired.

\section{Hypothesis 4 Results}

There was no statistically significant difference between students with 0 to $70 \%$ final course grades $(n=41)$ in comparison to professionalism grades in terms of attendance and punctuality. Consequently, the null hypothesis was retained, and the alternative hypothesis was rejected with final course grades 
$(M d n=63.43 \%)$ in comparison to professionalism grades $(M d n=65.52 \%, z=$ $1.808, p=0.071, r=-0.282)$. Using Cohen's criteria for $r$, this was a low effect size (Minium et al., 1999, p. 73). This level of effect size means that although it was not statistically significant, the difference in medians is low. Regarding meeting assumptions for the Wilcoxon signed-rank test, per the KolmogorovSmirnov test, nonnormality was confirmed with at $p=0.008$. As to the other two assumptions, both met requirements, were continuous, and were randomly and independently acquired.

\section{Hypothesis 5 Results}

There was a statistically significant difference between all student final course grades $(n=729)$ in comparison to professionalism grades in terms of attendance and punctuality. Consequently, the null hypothesis was rejected, and the alternative hypothesis was retained with final course grades $(M d n=91.35 \%)$ in comparison to professionalism grades $(M d n=98.28 \%, z=-12.263, p=0.000$, $r=-0.454)$. Using Cohen's criteria for $r$, this was a moderate effect size (Minium et al., 1999, p. 73). This level of effect size means that although statistically significant, the difference in medians is moderate. Regarding meeting assumptions for the Wilcoxon signed-rank test, per the KolmogorovSmirnov test, nonnormality was confirmed with at $p=0.000$. As to the other two assumptions, both met requirements, were continuous, and were randomly and independently acquired.

Table 1

\section{Conclusions and Future Research}

Null Hypotheses 1-5 Results

\begin{tabular}{lcccc}
\hline \multicolumn{1}{c}{ Null hypothesis } & Result & $\begin{array}{c}\text { Final } \\
\text { course } \\
\text { grade }^{\mathrm{a}}\end{array}$ & $\begin{array}{c}\text { Professionalism } \\
\text { grade }^{\mathrm{a}}\end{array}$ & $\begin{array}{c}p \text { - } \\
\text { value }\end{array}$ \\
\hline $\begin{array}{l}\text { Null Hypothesis 1: } \geq \\
\text { 90\% final grades }\end{array}$ & Rejected & $95.05 \%$ & $100.00 \%$ & 0.000 \\
$\begin{array}{l}\text { Null Hypothesis 2: } 80- \\
\text { 90\% final grades }\end{array}$ & Rejected & $86.25 \%$ & $93.33 \%$ & 0.000 \\
$\begin{array}{l}\text { Null Hypothesis 3: } 70- \\
\text { 80\% final grades }\end{array}$ & Rejected & $81.65 \%$ & $75.20 \%$ & 0.000 \\
$\begin{array}{l}\text { Null Hypothesis 4: 0- } \\
70 \% \text { final grades }\end{array}$ & Retained & $63.43 \%$ & $65.52 \%$ & 0.071 \\
$\begin{array}{l}\text { Null Hypothesis 5: All } \\
\text { final grades }\end{array}$ & Rejected & $91.35 \%$ & $98.28 \%$ & 0.000 \\
\hline
\end{tabular}

Note. For each null hypothesis, final course grades are compared to professionalism grades for that group of students. 
${ }^{a}$ Medians were used for Null Hypotheses 1, 2, 4, and 5, and means were used for Null Hypothesis 3.

Table 1 summarizes the study results. Study results indicate that professionalism grades, in terms of attendance and punctuality, were high (median of $93.33-100 \%$ ) for students earning 80 to $100 \%$ median final course grades. Students earning 70-80\% mean final course grades were less motivated to earn high professionalism grades - earning a $75.20 \%$ mean. There was little difference between final course grades and professionalism grades for students earning less than $70 \%$ (median) for a final course grade. The aggregate of all student final course grades (median of $91.35 \%$ ) in comparison to professionalism grades (median of $98.28 \%$ ) yielded a significant difference.

Based on the study results, classroom and $100 \%$ online students who earned a final course grade of $80 \%$ or higher were more concerned about class activities and therefore participated at a higher level than other students at less than $80 \%$. Because professionalism, in terms of attendance and punctuality, was a part of each course, students earning $80-100 \%$ final course grades treated professionalism as any other course objective - as tasks to be completed.

The part of the results that can't be quantified is if the professionalism tracking and grading efforts in each course, in terms of attendance and punctuality, will help these 729 students to be more responsible future workers in industry. Will they be more inclined to go to work and show up on time? Will they demonstrate an example of solid stewardship of their time and efforts for fellow workers to emulate? It is the hopes of this researcher, former industrial manager, and academic that students are now more aware of the need to be professional in their careers.

Recommended future research includes a study on tracking punctuality alone, aside from attendance. Researching missed and late assignments and projects may also be of benefit. Deif, Stark, Butler, and Olsen (2017) call for more research on the link between student success and first-day attendance. Flanigan, Benson, and Porter (2017) recommend future research on customer satisfaction models for millennials; however, the same type of research is needed for student satisfaction with the academic experience. The current study should also be repeated in order to replicate or refute its findings.

Stripling et al. (2013, p. 57) call for further research on why undergraduate students choose to skip class. The recommended focus would be on class size, class scheduling, class structure, class classification, instructor behavior and issues, student performance, personal issues, and learning activities.

For academics seeking to generate greater levels of student participation in their courses, Stripling et al. (2013, p. 57) also recommends the following to boost attendance and student satisfaction in their courses: take attendance, know the course content, develop quality lectures and class sessions, relate in-class work to assignments and assessments, plan rigorous courses, present course 
information in an interesting way, allow students to enter late, and develop teacher-student rapport.

\section{References}

Blad, E. (2018). 8 million students are "chronically absent," states say. Education Week, 38(3), 10.

Brauer, J. (1994). Correspondence: Should class attendance be mandatory? (First letter). Journal of Economic Perspectives, 8(3), 205-207. doi:10.1257/jep.8.3.205

Davis, J. L., \& McDonald, T. N. (2016). Online, handwritten or hybrid homework: What's best for our students in the long run? Journal of Online Engineering Education, 7(1), Article 1. Retrieved from http://www.onlineengineeringeducation.com/joee_v7n1a1.pdf

Deif, A., Stark, C., Butler, K., \& Olsen, E. (2017). Evaluation of career readiness at an industrial technology program using a fuzzy approach. The Journal of Technology, Management, and Applied Engineering, 33(1). Retrieved from https://cdn.ymaws.com/www.atmae.org/resource/resmgr/Evaluation_of_Car eer_Readine.pdf

Field, A. (2009). Discovering statistics using SPSS (3rd ed.). Thousand Oaks, CA: Sage.

Field, A. (2013). Discovering statistics using IBM SPSS statistics (4th ed.). Thousand Oaks, CA: Sage.

Flanigan, R., Benson, G., \& Porter, D. (2017). An assessment of millennial generation customer satisfaction in the industrial business-to-business market sector. The Journal of Technology, Management, and Applied Engineering, 33(2). Retrieved from https://cdn.ymaws.com/www.atmae.org/resource/resmgr/jtmae/An_Assess ment_of_Millennial_.pdf

Friedman, P., Rodriguez, F., \& McComb, J. (2001). Why students do and do not attend classes: Myths and realities. College Teaching, 49(4), 124-133. doi:10.1080/87567555.2001.10844593

Gump, S. E. (2004). The truth behind truancy: Student rationales for cutting class. Educational Research Quarterly, 28(2), 50-58.

Hollenbeck, C. J. (2009). Advancing professionalism on a shoestring budget. The Professional Lawyer, 19(3), 22-23, 27.

Kahveci, M. (2010). Student's perceptions to use technology for learning: Measurement integrity of the Modified Fennema-Sherman Attitudes Scales. The Turkish Online Journal of Educational Technology, 9(1), 185-201. Retrieved from http://www.tojet.net/articles/v9i1/9121.pdf

Keith, J. F., Stastny, S. N., \& Brunt, A. (2016). Barriers and strategies for success for American Indian college students: A review. Journal of College Student Development, 57(6), 698-714. doi:10.1353/csd.2016.0069 
Klay, W. E., Brower, R., \& Williams, B. (2001). A community-oriented model of academic professionalism. Metropolitan Universities, 12(3), 41-50. Retrieved from http://journals.iupui.edu/index.php/muj/article/view/19905

Korhonen, J. (2003). On the ethics of corporate social responsibilityConsidering the paradigm of industrial metabolism. Journal of Business Ethics, 48(4), 301-315. doi:10.1023/B:BUSI.0000005798.88294.31

Light, R. J. (1990). The Harvard Assessment Seminars: Explorations with students and faculty about teaching, learning, and student life: First report, 1990. Cambridge, MA: Harvard University Graduate School of Education.

Marburger, D. R. (2001). Absenteeism and undergraduate exam performance. Journal of Economic Education, 32(2), 99-109. doi:10.1080/00220480109595176

Professionalism. (2019). In Merriam-Webster.com Dictionary. Retrieved January 7, 2019 from https://www.merriamwebster.com/dictionary/professionalism

Minium, E. W., Clarke, R. C., \& Coladarci, T. (1999). Elements of statistical reasoning (2nd ed.). New York, NY: Wiley.

Moore, R. (2004). Does improving developmental education students' understanding of the importance of class attendance improve students' attendance and academic performance? Research \& Teaching in Developmental Education, 20(2), 24-39.

Moore, R. (2005). Attendance: Are penalties more effective than rewards? Journal of Developmental Education, 29(2), 26-30, 32.

Moore, R. (2006). Class attendance: How students' attitudes about attendance relate to their academic performance in introductory science classes. Research \& Teaching in Developmental Education, 23(1), 19-33.

National Academy of Engineering, Committee on Standards for K-12 Engineering Education. (2010). Standards for $K-12$ engineering education? Washington, DC: National Academies Press. doi:10.17226/12990

Oliver, R. L. (2010). Satisfaction: A behavioral perspective on the consumer (2nd ed.). New York, NY: Routledge. doi:10.4324/9781315700892

Ratanawongsa, N., Bolen, S., Howell, E. E., Kern, D. E., Sisson, S. D., \& Larriviere, D. (2006). Residents' perceptions of professionalism in training and practice: Barriers, promoters, and duty hour requirements. Journal of General Internal Medicine, 21(7), 758-763. doi:10.1111/j.15251497.2006.00496.x

Ritz, J. M., \& Bevins, P. S. (2012). Economics, innovations, technology, and engineering education: the connections. The Journal of Technology Studies, 38(2), 90-104. doi:10.21061/jots.v38i2.a.4

Rodgers, J. R. (2001). A panel-data study of the effect of student attendance on university performance. Australian Journal of Education, 45(3), 284-295. doi:10.1177/000494410104500306 
Romer, D. (1993). Do students go to class? Should they? Journal of Economic Perspectives, 7(3), 167-174. doi:10.1257/jep.7.3.167

Schunk, D. H. (2000). Learning theories: An educational perspective. Upper Saddle River, NJ: Merill/Prentice Hall.

Stripling, C. T., Roberts, T. G., \& Israel, G. D. (2013). Class attendance: An investigation of why undergraduates choose to not attend class. NACTA Journal, 57(3), 47-59.

Sullivan, W. D., Jr. (2018). A case study exploring international student engagement at three small, private colleges. Journal of International Students, 8(2), 977-1001. doi:10.32674/jis.v8i2.123

Thomas, P. V., \& Higbee, J. I. (2000). The relationship between involvement and success in developmental algebra. Journal of College Reading and Learning, 30(2), 222-232. doi:10.1080/10790195.2000.10850097

Van Blerkom, M. L. (1992). Class attendance in undergraduate courses. Journal of Psychology, 126(5), 487-494. doi:10.1080/00223980.1992.10543382

Wyatt, G. (1992). Skipping class: An analysis of absenteeism among first-year college students. Teaching Sociology 20(3), 201-207. doi:10.2307/1319061

Yau, H. K., \& Cheng, A. L. F. (2012). Gender difference of confidence in using technology for learning. The Journal of Technology Studies, 38(2), 74-79. doi:10.21061/jots.v38i2.a.2

Zhao, X., \& Stinson, T. A. (2006). Motivating students for better grades: A study of the relationship between absenteeism and student performance. The Journal of Learning in Higher Education, 2(2), 1-8.

\section{About the Author}

Jeffrey M. Ulmer (julmer@ucmo.edu) is Professor of Engineering Technology, Technology Management, and Industrial Management at the University of Central Missouri. 